\title{
Process Optimization of Microwave-assisted Extraction of Volatile Oil of Scindapsus aureus and Chemical analysis by GC-MS
}

\author{
WANG Gang ${ }^{1, a}$, SHENG Meng Mei ${ }^{1, a}$, GUO Die ${ }^{1, a}$ and HUANG Liang Qing ${ }^{1, a *}$ \\ ${ }^{1}$ Department of Physiology, Zunyi Medical College, Guizhou Zunyi 563003, China \\ awg8855350@163.com
}

Keywords: Flower of S. aureus ; the essential oil ; GC-MS ; Microwave extraction

\begin{abstract}
To determine optimum extraction process of volatile oil from flower of Scindepus aureus and analyze its chemical composition. The essential oils were extracted from $S$. aureus by microwave-assisted extraction (MAE), distillation time, solid-liquid ratio. Microwave Power were investigated with extraction ratio of volatile oil as index, extraction technology of volatile oil from flower of $S$. aureus was optimized by orthogonal test. Chemical composition of the volatile oil was analized by gas chromatography-mass spectrometry (GC-MS). The amount of the components from essential oil were determined by normalization method. The essential oils were identified with WileyNist05 and Nist05 mass spectrum atlas. Optimal extraction process of volatile oil was as follows: solid-liquid ratio $1: 14$.distillation time $4 \mathrm{~h}$ and microwave power $700 \mathrm{~W}$. There were 45 components that composed of about $81.94 \%$ of the total essential from Scindepus aureus. by MAE oil and they were separated and identified. The study provided scientific basis for further exploration and utilization of $S$. aureus.
\end{abstract}

\section{Introduction}

Scindapsus aureus, a perennial evergreen vine plant of genus S. araceae, is mild-natured with sweet flavor and mainly grows in high altitude areas over one thousand kilometers in Sichuan province, Guizhou province and Guangxi province in China. S. aureus is bland and mild, with no poisons and the functions of decreasing internal heat, promoting flow of pneuma and blood circulation ${ }^{[1-4]}$. It is found through modern pharmacological researches that $S$. aureus has the effects of antidiabetic, hypotensive, softening artery blood vessel and increasing coronary artery flow. Long term use of drinks containing $S$. aureus also helps to delay cell senescence and improve immunity ${ }^{[5-6]}$. MAE has been shown to promote the extraction content of bioactive components from a wide variety of herbs ${ }^{[7]}$. Compared with the conventional extraction techniques, MAE is a simpler and cheaper method, which is suitable for processing wider varieties of raw materials with less limitation to the polarity of solvent ${ }^{[8]}$. At the same time, only a few minutes are required in MAE, while the conventional extraction techniques usually need several hours. So far, there was no report concerning the MAE of volatile oil from $S$. aureus. The aim of this study was to optimize the MAE of volatile oil and analyze its constituents by GC-MS from S. aureus.

\section{Chemicals and Methods}

\section{Materials and Chemicals}

S. aureus was purchased from Fukang traditional Chinese medicine Co.,Ltd (Zunyi, Guizhou province). The crushed powder was kept in a vacuum dryer until use. Diethyl ether and anhydrous sodium sulfate used in this experiments were as of analytical grade and purchased from Changzheng Chemical Reagent Co., Ltd (Shanghai, China).

\section{Optimization of Microwave-assisted extraction}

Technological process. XH-100A microwave-assisted extraction apparatus $(2450 \mathrm{MHz}$, Xianghao Microwave Instrument Co., Ltd.) equipped with a programmable heating power from 0 to $800 \mathrm{~W}$ with $0.1 \%$ increment was used. 9 specimens of $S$. aureus were prepared and each of specimens weighed exactly $(100.0 \mathrm{~g})$ and placed in a $2000 \mathrm{~mL}$ round bottom flask extraction 
equipped with reflux system. All of the experiments were performed under a set of microwave power (between $100 \mathrm{~W}$ and $1000 \mathrm{~W}$ ) for a certain period of time (between $1 \mathrm{~h}$ and $3 \mathrm{~h}$ ) in a set of solvent volume (between 1:10 and 1:14). When the extraction completed, the distillate is extracted three times by using diethyl ether $(20 \mathrm{~mL} \times 3)$. And then $30 \mathrm{~g}$ of anhydrous sodium sulfate was added into the extractive to remove water The extractive was filtrated and concentrated to acquire the volatile oil with RE-5000A rotary evaporator (Yarong Scientific and Technology Company, Shanghai, China) at $50{ }^{\circ} \mathrm{C}$. The volatile oil was further dried in a vacuum dryer to remove the residual solvent. In this study, all of the experiments were performed in triplicates, and the results reported here were the means of the three trials.

Orthogonal Experimental Design. The yield of volatile oil from $S$. aureus is taken as an indicator in the study and a three-factor and three-level orthogonal experiment is designed, where the three factors include extraction time, liquid to solid ratio and microwave power. The experiment is scheduled in accordance with Table $\mathrm{L}_{9}\left(3^{4}\right)$. Factors and levels of orthogonal test listed in Table 1 .

Table 1 Factors and Levels

\begin{tabular}{ccc}
\hline A (microwave power, $w)$ & B (liquid to solid ratio, $\mathrm{g} / \mathrm{ml}$ ) & $\mathrm{C}($ Extract time, $\mathrm{h})$ \\
\hline 300 & $1: 10$ & 1.0 \\
500 & $1: 12$ & 2.5 \\
700 & $1: 14$ & 4.0 \\
\hline
\end{tabular}

Extraction yield determination. S. aureus was calculated using the following formula:

$$
\mathrm{EY}=\frac{m_{e}}{m_{t}} \times 100 \%
$$

Where $\mathrm{m}_{\mathrm{e}}$ is the mass of volatile oil extracted in the solution $(\mathrm{g})$ and $\mathrm{m}_{\mathrm{t}}$ is the mass of $S$. aureus (g).

\section{GC-MS Analysis}

The essential oil of S. aureus were analyzed by GC-MS $6890 \mathrm{~N}-5973$ insert with HP-5MS capillary column (Agilent, USA) ${ }^{[4]}$. Gas Chromatography Conditions was as follows: vaporizing chamber temperature was $260^{\circ} \mathrm{C}$; high-purity hydrogen $(99.999 \%)$ was used as carrier gas, carrier gas flow rate was $1.0 \mathrm{~mL} / \mathrm{min}$, injection volume was $1 \mu \mathrm{L}$ and split ration was $20: 1$. The temperature programs were $70{ }^{\circ} \mathrm{C}(5 \mathrm{~min})$ to $145^{\circ} \mathrm{C} \quad(10 \mathrm{~min})$ at a rate of $3{ }^{\circ} \mathrm{C} / \mathrm{min}$, then to $200{ }^{\circ} \mathrm{C}(10$ min) at a rate of $2{ }^{\circ} \mathrm{C} / \mathrm{min}$, then to $230{ }^{\circ} \mathrm{C}(10 \mathrm{~min})$ at a rate of $7{ }^{\circ} \mathrm{C} / \mathrm{min}$. The injector temperature was $260{ }^{\circ} \mathrm{C}$, the injection volume was $1.0 \mu \mathrm{L}$, split ratio was $20: 1$, carrier gas was He with at a rate of $1 \mathrm{~mL} / \mathrm{min}$; temperature of MS transfer line was $280{ }^{\circ} \mathrm{C}$.

Mass Spectrum Condition was as follows: EI source was used as ion source; ion source temperature was $230^{\circ} \mathrm{C}$; quadrupole rod temperature was $150^{\circ} \mathrm{C}$; electron energy was $70 \mathrm{eV}$; emission current was $34.6 \mu \mathrm{A}$; multiplier voltage was $1994 \mathrm{kV}$; interface temperature was $250^{\circ} \mathrm{C}$; solvent delayed $4 \mathrm{~min}$; mass ranged 10 550 amu. Scan range was10 550amu. The components in the essential oils of fresh materials were identified by comparison of their mass spectra with those of Winnist05. L and Nist05. L library data.

\section{Results and discussion}

\section{Optimization results of extraction conditions}

It could be found through intuitive analysis and variance analysis in the orthogonal experiment that the influence of various factors about the extraction conditions of essential oils was extraction time (C) $>$ Microwave power (A) $>$ liquid to solid ratio (B). As shown in variance analysis (See Table 3), microwave power has significant influence on yield of volatile oil from $S$. aureus while the other two factors do not have significant influences. The optimal process combination for microwave assisted extraction of volatile oil is $\mathrm{A}_{3} \mathrm{~B}_{3} \mathrm{C}_{3}$, which means the microwave power was $700 \mathrm{~W}$, the extraction time was $4.0 \mathrm{~h}$ and the liquid to solid ratio was 1:14. 
Table 2 Experiment scheme and results

\begin{tabular}{cccccc}
\hline No. & A & B & C & D (Deviation) & Extraction Yield $/ 100 \%$ \\
\hline 1 & 1 & 1 & 1 & 1 & 0.51 \\
2 & 1 & 2 & 2 & 2 & 0.43 \\
3 & 1 & 3 & 3 & 3 & 0.65 \\
4 & 2 & 1 & 2 & 3 & 0.59 \\
5 & 2 & 2 & 3 & 1 & 0.65 \\
6 & 2 & 3 & 1 & 2 & 0.69 \\
7 & 3 & 1 & 3 & 2 & 0.80 \\
8 & 3 & 2 & 1 & 3 & 0.73 \\
9 & 3 & 3 & 2 & 1 & 0.68 \\
K1 & 0.530 & 0.633 & 0.643 & 0.613 & \\
K2 & 0.643 & 0.603 & 0.567 & 0.640 & \\
K3 & 0.737 & 0.673 & 0.700 & 0.657 & \\
$R$ & 0.207 & 0.070 & 0.133 & 0.044 & \\
\hline
\end{tabular}

Table 3 Variance analysis

\begin{tabular}{lcccc}
\hline \multicolumn{1}{c}{ Table 3 Variance analysis } & \multicolumn{2}{c}{$\mathrm{F}_{0.05}(2,2)=19.00$} & \\
\hline Source of Variation & $\begin{array}{c}\text { Degrees of } \\
\text { Freedom }\end{array}$ & $\begin{array}{c}\text { Sum of } \\
\text { Deviation } \\
\text { Square }\end{array}$ & F-ratio & $\begin{array}{c}\text { Significant } \mathrm{F} \\
\text { Value }\end{array}$ \\
\hline Microwave power/A & 2 & 0.064 & 21.333 & $*$ \\
Liquid to solid & 2 & 0.007 & 2.333 & \\
ratio / B & 2 & 0.027 & 9.000 & \\
Extract time/C & 2 & 0.003 & 1.000 & \\
Deviation/D & & & & \\
\hline
\end{tabular}

\section{Verification Experiment}

Three batches of specimens are prepared in accordance with the optimal extraction conditions of volatile oil from $S$. aureus. The result is reliable and stable, as shown in Table 4.

\begin{tabular}{cc} 
Table 4 Results of content found in specimens $(\mathrm{n}=3)$ \\
\hline Batch No. & Yield of Volatile Oil \\
\hline 131101 & 0.87 \\
131102 & 0.85 \\
131103 & 0.83 \\
\hline
\end{tabular}

\section{Chemical constituents of the essential oils}

Essential oils from flower of S. aureus Hieron with microwave-assisted extraction were analyzed by GC /MS. The identified constituents and their related percentages were shown in Table 5 and the chromatogram was shown in Fig.1. 78 components are separated and 45 compounds are identified by using Nist05 and WILLEY standard mass spectrum database combined with related documents [7]. The relative content of each chemical component was obtained on basis of the peak area normalization method (See Table 5).

The essential oil constituents are classified into hydrocarbon $(40.36 \%)$, terpene $(24.30 \%)$, aldehyde $(8.72 \%)$, fatty acid $(6.92 \%)$ and others $(1.94 \%)$. 78 components are obtained from the volatile oil, accounting for $81.94 \%$ of the total amount of volatile oil. Components with relatively high content include beta-pinene (5.65\%), asarone (8.66 \%), n-octadecane (19. 50\%), $\beta$-ionone $(1.77 \%)$, lauric acid $(2.29 \%)$, farnesene $(1.85 \%)$ and myristic acid $(1.89 \%)$, and other components have relatively low content. In conclusion, this article provides a technique to analyze its volatile oil by using GC-MS, especially for separation of each chemical constituent. 


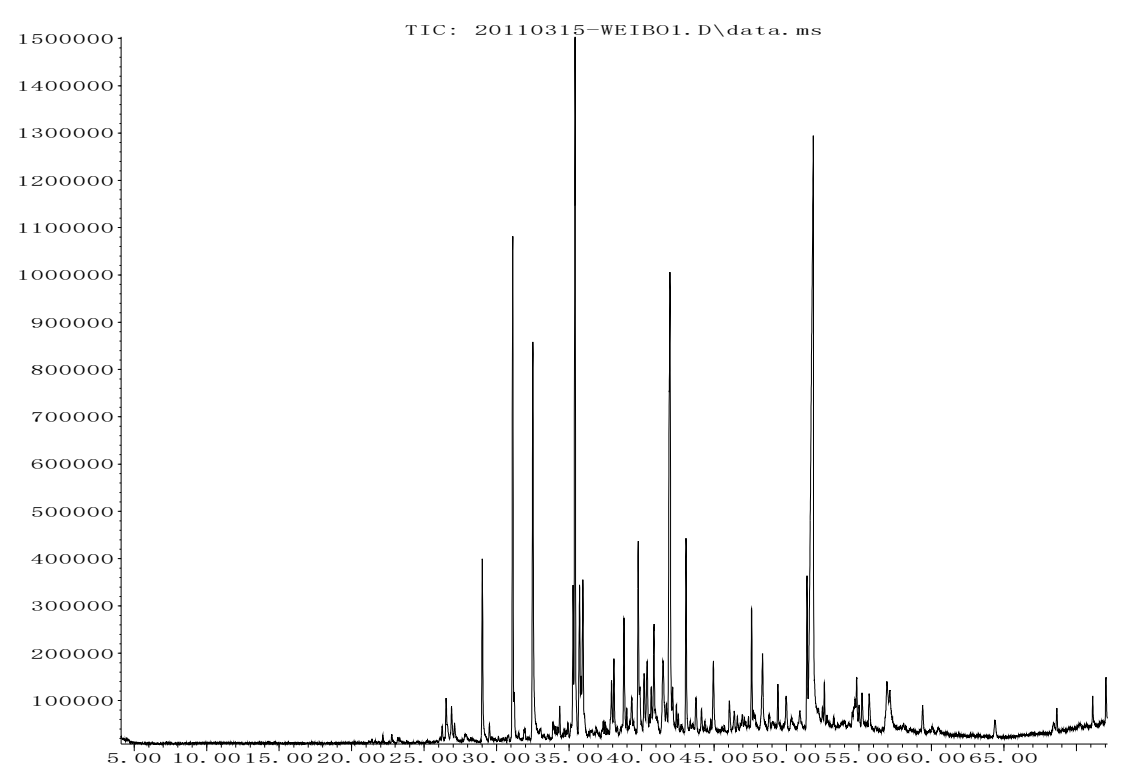

Fig. 1 Total ion current of S. aureus

Table 5 chemical constituent comparison of Volatile Oil from S. aureus

\begin{tabular}{|c|c|c|c|c|}
\hline No. & compounds & retain time $/ \mathrm{min}$ & formula & content $/ \%$ \\
\hline 1 & Ethylbenzene & 25.944 & $\mathrm{C}_{10} \mathrm{H}_{16}$ & 0.37 \\
\hline 2 & p-Xylene & 26.521 & $\mathrm{C}_{10} \mathrm{H}_{14} \mathrm{O}$ & 0.82 \\
\hline 3 & 1,3-dimethyl- Benzene & 26.894 & $\mathrm{C}_{10} \mathrm{H}_{14} \mathrm{O}$ & 0.61 \\
\hline 4 & 1,2,3-trimethyl- Benzene & 27.105 & $\mathrm{C}_{9} \mathrm{H}_{10} \mathrm{O}_{2}$ & 0.30 \\
\hline 5 & 4-ethyl-1,2-dimethyl- Benzene & 29.017 & $\mathrm{C}_{10} \mathrm{H}_{12} \mathrm{O}_{2}$ & 2.50 \\
\hline 6 & 1-methyl-3-(1-methylethyl)- Benzene & 29.509 & $\mathrm{C}_{10} \mathrm{H}_{12} \mathrm{O}_{2}$ & 0.18 \\
\hline 7 & beta-Pinene & 31.956 & $\mathrm{C}_{11} \mathrm{H}_{14} \mathrm{O}_{2}$ & 5.65 \\
\hline 8 & Thymol & 32.501 & $\mathrm{C}_{9} \mathrm{H}_{10} \mathrm{O}_{3}$ & 0.21 \\
\hline 9 & 2-methyl-5-(1-methylethyl)- Phenol & 33.895 & $\mathrm{C}_{9} \mathrm{H}_{10} \mathrm{O}_{3}$ & 6.10 \\
\hline 10 & 1-(3-methoxyphenyl)- Ethanone & 33.971 & $\mathrm{C}_{11} \mathrm{H}_{14} \mathrm{O}_{2}$ & 0.70 \\
\hline 11 & Eugenol & 34.256 & $\mathrm{C}_{18} \mathrm{H}_{36} \mathrm{O}$ & 0.20 \\
\hline 12 & 4-ethenyl-1,2-dimethoxy- Benzene & 34.921 & $\mathrm{C}_{14} \mathrm{H}_{28}$ & 0.18 \\
\hline 13 & 1,2-dimethoxy-4-(2-propenyl)- Benzene & 35.278 & $\mathrm{C}_{12} \mathrm{H}_{24} \mathrm{O}_{2}$ & 0.51 \\
\hline 14 & 4-(2,6,6-trimethyl-2-cyclohexen)- Buten & 35.413 & $\mathrm{C}_{15} \mathrm{H}_{24} \mathrm{O}$ & 1.77 \\
\hline 15 & 1-(4-methoxyphenyl)-Ethanone & 35.840 & $\mathrm{C}_{16} \mathrm{H}_{32} \mathrm{O}$ & 8.72 \\
\hline 16 & Methyl eugenol & 37.482 & $\mathrm{C}_{15} \mathrm{H}_{24}$ & 0.65 \\
\hline 17 & Octadecanal & 38.794 & $\mathrm{C}_{15} \mathrm{H}_{24}$ & 0.16 \\
\hline 18 & (E)-2-Tetradecene & 39.772 & $\mathrm{C}_{15} \mathrm{H}_{26} \mathrm{O}$ & 1.79 \\
\hline 19 & Dodecanoic acid & 39.886 & $\mathrm{C}_{12} \mathrm{H}_{16} \mathrm{O}_{3}$ & 2.29 \\
\hline 20 & 2,6-Di-tert-butyl-4-methylphenol & 40.177 & $\mathrm{C}_{15} \mathrm{H}_{24} \mathrm{O}$ & 0.71 \\
\hline 21 & Hexadecanal & 40.388 & $\mathrm{C}_{15} \mathrm{H}_{22}$ & 0.93 \\
\hline 22 & alpha-Cedrene & 40.858 & $\mathrm{C}_{15} \mathrm{H}_{26} \mathrm{O}$ & 1.30 \\
\hline 23 & farnesene & 41.717 & $\mathrm{C}_{15} \mathrm{H}_{26} \mathrm{O}$ & 1.85 \\
\hline 24 & Cedrol & 41.965 & $\mathrm{C}_{18} \mathrm{H}_{36} \mathrm{O}$ & 0.44 \\
\hline 25 & Asarone & 43.073 & $\mathrm{C}_{12} \mathrm{H}_{16} \mathrm{O}_{3}$ & 8.66 \\
\hline 26 & Agarospirol & 43.359 & $\mathrm{C}_{17} \mathrm{H}_{36}$ & 0.17 \\
\hline 27 & 4-(1,2,2-trimethylcyclopentyl)- Benzene & 44.137 & $\mathrm{C}_{16} \mathrm{H}_{32} \mathrm{O}$ & 2.34 \\
\hline 28 & tau-Muurolol & 46.060 & $\mathrm{C}_{10} \mathrm{H}_{12} \mathrm{O}_{4}$ & 0.19 \\
\hline 29 & alpha.-Cadinol & 47.594 & $\mathrm{C}_{14} \mathrm{H}_{28} \mathrm{O}_{2}$ & 1.23 \\
\hline
\end{tabular}




\begin{tabular}{llccc}
30 & Octadecanal & 48.794 & $\mathrm{C}_{18} \mathrm{H}_{38}$ & 0.50 \\
31 & Asarone & 49.409 & $\mathrm{C}_{18} \mathrm{H}_{36} \mathrm{O}$ & 1.27 \\
32 & Heptadecane & 49.977 & & 0.24 \\
33 & Hexadecanal & 51.419 & $\mathrm{C}_{19} \mathrm{H}_{40}$ & 0.44 \\
34 & 2,4,5-trimethoxy- Benzaldehyde & 51.846 & $\mathrm{C}_{6} \mathrm{H}_{6} \mathrm{Cl}_{8} \mathrm{O}$ & 0.59 \\
35 & Tetradecanoic acid & 52.488 & $\mathrm{C}_{16} \mathrm{H}_{22} \mathrm{O}_{4}$ & 1.89 \\
36 & Octadecane & 52.618 & $\mathrm{C}_{16} \mathrm{H}_{32} \mathrm{O}_{2}$ & 19.50 \\
37 & 6,10,14-trimethyl-2-Pentadecanone & 54.736 & $\mathrm{C}_{18} \mathrm{H}_{22} \mathrm{O}_{2}$ & 0.25 \\
38 & N-Hydroxy-N'-(2-phenyl)-niotinamidine & 55.216 & $\mathrm{C}_{20} \mathrm{H}_{42}$ & 0.45 \\
39 & Nonadecane & 55.708 & $\mathrm{C}_{15} \mathrm{H}_{12} \mathrm{O}_{2}$ & 0.64 \\
40 & 1,1'-oxybis[2,3,3,3-tetrachloro]- Propane & 56.929 & $\mathrm{C}_{21} \mathrm{H}_{42}$ & 0.47 \\
41 & Dibutyl phthalate & 57.134 & $\mathrm{C}_{21} \mathrm{H}_{44}$ & 0.55 \\
\hline 42 & n-Hexadecanoic acid & 59.398 & $\mathrm{C}_{14} \mathrm{H}_{26} \mathrm{O}_{2}$ & 1.48 \\
43 & Hexadecanoic acid, ethyl ester & 64.389 & $\mathrm{C}_{18} \mathrm{H}_{32} \mathrm{O}_{2}$ & 1.26 \\
44 & Eicosane & 68.651 & $\mathrm{C}_{20} \mathrm{H}_{42}$ & 0.49 \\
45 & 1,3-diphenyl-1,3-Propanedione & 71.131 & $\mathrm{C}_{12} \mathrm{H}_{26}$ & 0.39 \\
\hline
\end{tabular}

\section{Discussion}

S. aureus contains a number of biologically active chemical components and its volatile oil is mainly composed of terpenes, fatty acids and alkanes. Terpene refers to hydrocarbons in nature of which the molecular formula is several times of isoprene and their oxygen-carrying derivatives. It has many physiological activities, such as expectorant, cough relief, carminative, sweating, anthelminthics and analgesia etc ${ }^{[10]}$.

This experiment adopts GC-MS to analyze and study the components of volatile oil from $S$. aureus and has scientific significance to the exploration and utilization of Scindepus aureus resources.

\section{Acknowledgements}

The study was funded by 2010 modernization of Chinese Traditional Medicine Support Project (No. [2010]5012), Guizhou province, China.

\section{References}

[1] Karimi, H. R. and Sajjadinia, A. Preliminary evaluation of composted pistachio hull and rice husk as potting medium on scindapsus aureus vegetative and physiological characteristics in greenhouse condition [J]. Journal of plant nutrition, 2014, 36(14):2225-2235.

[2] 주진희. Effect of Scindapsus aureus and Syngonium podophyllum on the Improvement in Indoor Humidity by a Difference of Hydoroculture Volume Ratio and Pot Media [J]. Journal of the Korean Institute of Landscape Architecture, 2011, 37(4):94-99.

[3] Zhu Qin, Zhang Kun, Du Zhiyun, et al. Inhibition and antioxidation of extracts from Scindepus aureus in Tibet on $\alpha$-glucosidase [J]. Chinese Herbal Medicines, 2009, 32(1):89-92.

[4] Li Wenmao, Shi Yuping, Liu Chunying et al. Researches on extraction process of flavones in Scindepus aureus [J]. Northern Horticulture, 2013(05): 144-146.

[5] Luo Xiaowen, Gu Jian, Zhang E et al. Experimental research on hypoglycemic effect of various active sites of Scindepus aureus [J].Chinese Hebal Medicines, 2012, 35(4): 612-614.

[6] Wei Yongsheng, Zheng Minyan, Geng Wei et al. Analysis and measurement of mineral elements in Scindepus aureus in Tibet [J]. Chemistry and Industry of Forest Products, 2013, 33(1): 102-106. 
[7] LUCCHESI M E, CHEMAT F, SMADJA J. Solvent-free microwave extraction of essential oil fromaromatic herbs: comparison with conventional hydro-distillation[J]. Journal of Chromatography A, 2009, 1043 (2): 323-327.

[8] GAO Shan, HAN Wei, DENG Xiu. Study of the mechanism of microwave-assisted extraction of Mahoniabealei (Fort.) leaves and Chrysanthemum morifolium (Ramat.) petals [J]. Flavor and Fragrance Journal, 2011, 19(3): 244-250.

[9] Cong Puzhu. Application of mass spectroscopy in natural organic chemistry[M]. Beijing: Science Press, 1987.

[10]He Yuanchuan, Chen Shijiang, He Zongyi et al. Progress of researches on antrodia camphorata and triterpene $[\mathrm{J}]$. Chongqing Journal of Research on Chinese Drugs and Herbs, 2012, 2(66):19-25. 